Professor David Vital of Bar-Ilan University, Israel, says that there is good reason to believe that none of the existing nuclear powers contemplates a policy founded on the use or threat of nuclear force. Is this true of the European security policy of either the NATO powers or the Soviet Union?

Perhaps the most important thesis in the book comes right at the end. It is a proposed policy for reactor exporters - one which recognizes that a safeguard systom based on inspection is inadequate to the load which nonproliferation will place on it. "The cause of preventing the proliferation of nuclear weapons would be best served," Barnaby writes, "if the major reactor-exporting countries agreed between themselves to export reactors only if the receiving countries agree to a scheme by which the plutonium produced is removed from their immediate possession." This is the urgent problem and it is one which governments are ignoring. They are taking refuge in the argument that if they do not export the reactors somebody else will. They are stimulating plutoniumproducing facilities around the world (and now uranium enrichment facilities in the form of gas centrifuges may be following) by false economic argument and massive subsidy. The results are already there in four or five countries. Pugwash has asked all the right questions. What is needed now is some follow through. Whose responsibility is it? LEONARD BEATON

\section{PROVOCATIVE PHYSICS}

Essays in the History of Mechanics

By C. Truesdell. Pp. $x+384$. (Springer-Verlag: Berlin and New York, 1968.) 78 DM; $\$ 19.60$.

Professor Truespel conceives rational mechanics as a science of very wide scope: it does not merely deal with the motions of mass-points, but with all mechanical and thermal properties of continuous media. Rational mech. anics, thus taken lato sensu, is, he contends, a part of mathematies, like geometry; by this he means that it is ripe for axiomatic treatment; and, indeed, he has founded a school of brilliant mathematicians actively pursuing an extensive programme of axiomatization of the whole domain, coupling logical rigour with a striving for utmost generalization of the basic concepts and laws. It is in the same spirit that he approaches the history of the subject, and it is therefore not surprising that he arrives at highly original conclusions. These would be unimpeachable if they were given for what they actually pertain to: the development of one important aspect of scientific thinking. The author, however, loaves us in no doubt that he regards this aspect as the only one worth considering, and this spoils to some extent the balance of his account. Thus he shares the fashion of the day in extolling the formal stammerings of the schoolmen (has he really read them?) and shows no feeling for the fiery spirit of Galileo. He is obviously at his best whon ho deals with the period in which great effort was spent in formulating the fundamental principles and building up the methods of analysis of his science of prodilection: the time of Newton and, abovo all, the following period, dominated by Euler's impressive genius. There he has done pioneering work; his investigations on tho growth of the theory of elasticity during the 18th century, exclusively based on the study of the sources, are of the highest standard and fill a large gap in our knowledge of the development of the basic mechanical conceptions.

To do full justico to Truesdell's contributions both to history and to contemporary science, mention must be made of the perfection of the style in which he presents them-a quality all too rare in our barbarous, technologist-ridden timo. Thus the book under reviow, in which he has collected eight of his most important papers both on the history and the method of rational mech- anics, is not only exquisitely printed, but provided with beautiful, well chosen illustrations, which add their own charm to that of the text. Sound scholarship, depth and lucidity of argumentation would suffice to make these essays enjoyable as well as instructive and stimulating; but they acquire a piquancy of their own from the pungent humour which pervades them-a true mirror of the author's forceful personality. Impatient of anything that smacks of narrowmindedness, sham or intellectual cowardice, he lavishes sarcasm and wit in relentless exposure of the many shortcomings of past and present scientists in their attitude to the historical and logical aspects of the growth and foundation of science. Indeed, when we learn from notices appended to each of the essays that they formed the texts of lectures delivered at numerous places of learning all over the world, we cannot help picturing Truesdell as the knight errant of the true spirit of scientific humanism. Knights errant, as is well known, are liable to be ensnared by enchantresses, who contrive to benumb their judgment; and physicists may feel that our author, succumbing to the spell of the queen of sciences, sometimes fails to appreciate their own mode of approach to the problems. Trenchant opinions, however, proffered with candour and directness, need not mislead the critical reader; they may sound provoking to physicists inclining to pomposity; those with an alert mind will find them provocative.

L. Rosenfeid

\section{PHILOSOPHY OR SCIENCE OF SPACE AND TIME}

\author{
Geometry and Chronometry in Philosophical Per- \\ spective
}

By Adolph Grünbaum. Pp. viii +378. (University of Minnesota Press: Minneapolis; Oxford University Press: London, March 1969.) $100 s$ boards; $27 s 6 d$ paper.

CHAPter one is a reprint of Grünbaum's essay Geometry, Chronometry and Empiricism of $1962^{1}$, which has meanwhile been criticized in H. Putnam's Examination of Grünbaum's Philosophy of Geometry ${ }^{2}$. Chapter two is not a reprint of Putnam's paper, but chapter three, also published elsewhere ${ }^{3}$, is Grünbaum's reply to it.

The second chapter is principally concerned with an old question revived by $\mathrm{G}$. Schlesinger, whether it could be detected if "everything had been doubled in size overnight". It is nowhere stated in what kind of cross section through four-dimensional space-time the "nocturnal" doubling of all lengths is imagined to occur. Nor is it stated what happens to the other physical quantities. Are all velocities doubled, for example, or all time intervals? Are all masses halved or $h c$ ? Are dimensionless quantities like $e^{2} / h c$ left unchanged? A consistent unambiguous definition, if possible at all, would at least require the clear context of a definite physical theory before and after the doubling and definite boundary conditions in between. The discussion in chapter two seems a game with such ill-defined rules that it could hardly be played in an intelligent way. It discloses a quasi-physical reasoning, which seems typical for the whole book and which in my opinion could hardly be accepted by modern physicists and does not lead anywhere.

The nocturnal puzzle may be seen altogether as an illustration, although perhaps not the most illuminating one, of the general theme of the book. If the topology of physical space or time or space-time is, say, continuous, the metric cannot intrinsically be determined from it. The problem is roughly in how far the choice of the topological parametrization by coordinates $x^{\alpha}$ and of the metric by the tensor $g_{\alpha \beta}(x)$ in cvery point $x$ is confined by topological or geometrical or physical conditions and in how far there remains freedom for conventions, which 